

INFOMATEK

Volume 19 Nomor 1 Juni 2017

\title{
STUDI LAJU DEOKSIGENASI PADA SUNGAI CIKAPUNDUNG UNTUK RUAS SILIWANGI - ASIA AFRIKA, BANDUNG
}

\author{
Yonik Meilawati Yustiani, Astri Hasbiah", Muhammad Pahlevi Wahyu Saputra \\ Program Studi Teknik Lingkungan \\ Fakultas Teknik - Universitas Pasundan
}

\begin{abstract}
Abstrak: Sungai Cikapundung merupakan sungai terbesar di kota Bandung. Di pinggiran sungai dipadati oleh rumah-rumah penduduk dengan saluran buangannya yang langsung mengarah ke sungai. Buangan yang berasal dari kegiatan domestik dan industri yang tersuspensi dalam sungai dapat mempengaruhi penurunan kualitas air pada Sungai Cikapundung. Berbagai upaya dapat dilaksanakan dalam rangka perbaikan kondisi lingkungan Sungai Cikapundung. Salah satu kegiatan yang dapat dilakukan adalah prediksi kualitas airnya melalui pemodelan. Model kualitas untuk sungai yang tercemar limbah domestik pada umumnya menggunakan persamaan BOD dan DO. Studi ini diarahkan untuk mengetahui nilai koefisien laju deoksigenasi aktual air Sungai Cikapundung untuk ruas padat penduduk. Pengambilan sampel dilakukan pada lima titik lokasi yang dianggap dapat mewakili kondisi sungai dengan jumlah kepadatan penduduk. Metode analisis laboratorium yang digunakan dalam perhitungan laju deoksigenasi yaitu menggunakan Metode Winkler dan Metode Slope, sedangkan Rumus Empiris yang digunakan dalam perhitungan laju deoksigenasi menggunakan Rumus Persamaan Hydroscience untuk aliran normal. Hasil perhitungan menunjukkan bahwa nilai rentang laju deoksigenasi $\left(\mathrm{K}_{1}\right)$ pada Sungai Cikapundung berkisar antara 0,03 hingga 0,24 per hari dan nilai rentang BOD Ultimate (La) berkisar antara 6,42 hingga $15,75 \mathrm{mg} / \mathrm{L}$. Sedangkan untuk nilai rentang laju deoksigenasi $\left(\mathrm{K}_{1}\right)$ pada Sungai Cikapundung dengan menggunakan rumus empiris berkisar antara 0,50 hingga 0,66 per hari.
\end{abstract}

Kata kunci: Laju deoksigenasi, Sungai Cikapundung

\section{PENDAHULUAN}

Sungai merupakan suatu bentuk ekosistem yang berperan penting dalam daur hidrologi dan berfungsi untuk memenuhi kebutuhan hidup bagi organisme atau populasi yang ada di daerah sekitarnya. Kondisi suatu sungai sangat berhubungan dengan karakteristik yang dimiliki oleh lingkungan yang ada di sekitarnya. Sungai sebagai suatu ekosistem, tersusun dari komponen biotik dan abiotik dan

\footnotetext{
*) astrihasbiah@unpas.ac.id
}

setiap komponen tersebut membentuk suatu jalinan fungsional yang saling memengaruhi (Rahayu dkk. [1]).

Sungai Cikapundung merupakan sungai terbesar di kota Bandung, daerah hulunya berada di Lembang dan hilirnya di Dayeuh Kolot yang akhirnya bergabung dengan sungai Citarum. Daerah sekitar sungai Cikapundung telah mengalami beberapa perubahan, bagian hulu sungai beralih fungsi lahan yang tadinya 
daerah hutan menjadi daerah peternakan dan pertanian. Sedangkan hilir sungai, daerah pemukiman warga sekarang telah menjadi pemukiman yang sangat padat penduduk dan sebagian menjadi daerah konveksi atau industri [1].

Sungai Cikapundung memiliki total panjang 28 kilometer, $\quad 15,50$ kilometer diantaranya melintasi Kota Bandung dan sekitar 10,57 km di pinggiran sungainya dipadati oleh rumahrumah penduduk dengan saluran buangannya yang langsung mengarah ke sungai (Robiahadawiyah [2]).

Buangan yang berasal dari kegiatan domestik dan industri yang tersuspensi dalam sungai dapat mempengaruhi penurunan kualitas air pada Sungai Cikapundung. Berbagai upaya dapat dilaksanakan dalam rangka perbaikan kondisi lingkungan sungai cikapundung. Salah satu kegiatan yang dapat dilakukan adalah prediksi kualitas airnya melalui pemodelan. Model kualitas untuk sungai yang tercemar limbah domestik pada umumnya menggunakan persamaan BOD (biogeochemical oxygen demand) dan DO (dissolved oxygen). Persamaan ini melibatkan laju deoksigenasi yang mempresentasikan proses penguraian mikroorganisme aerob, dimana mikroorganisme aerob ini membutuhkan keberadaan oksigen yang terlarut dalam air.
Laju deoksigenasi adalah kecepatan penurunan nilai oksigen yang terlarut di dalam air karena telah digunakan oleh bakteri aerob untuk menguraikan zat-zat organik yang dapat menurunkan kualitas air sungai. BOD adalah jumlah oksigen yang dibutuhkan oleh mikroorganisme untuk menguraikan (mengoksidasikan) hampir semua zat organik yang terlarut dan sebagian zat-zat organik yang tersuspensi dalam air. Kualitas Air adalah kondisi kalitatif yang diukur berdasarkan parameter tertententu seperti parameter fisika, kimia, dan biologi. DO merupakan salah satu parameter kimia yang dilakukan pengukuran dalam penelitian kali ini, karena DO kualitas air merupakan oksigen terlarut di dalam air dimana DO memiliki peranan penting bagi biota di perairan untuk membantu proses metabolisme.

Oleh karena itu, perlu adanya penelitian tentang laju deoksigenasi dengan segmen yang lebih banyak di daerah aliran Sungai Cikapundung dengan dilihat dari jumlah kepadatan penduduk yang tinggi.

\section{METODOLOGI}

\subsection{Lokasi Penelitian}

Penelitian yang dilakukan dalam studi ini adalah penelitian dalam skala laboratorium. Sungai yang dipilih sebagai tempat pengambilan sampel adalah Sungai Cikapundung. Dalam penelitian ini terdapat 
beberapa tahapan yang akan dilakukan dalam penyusunan laporan tentang menentukan laju deoksigenasi pada Sungai Cikapundung. Untuk lokasi penelitian dapat dilihat pada Gambar 1.

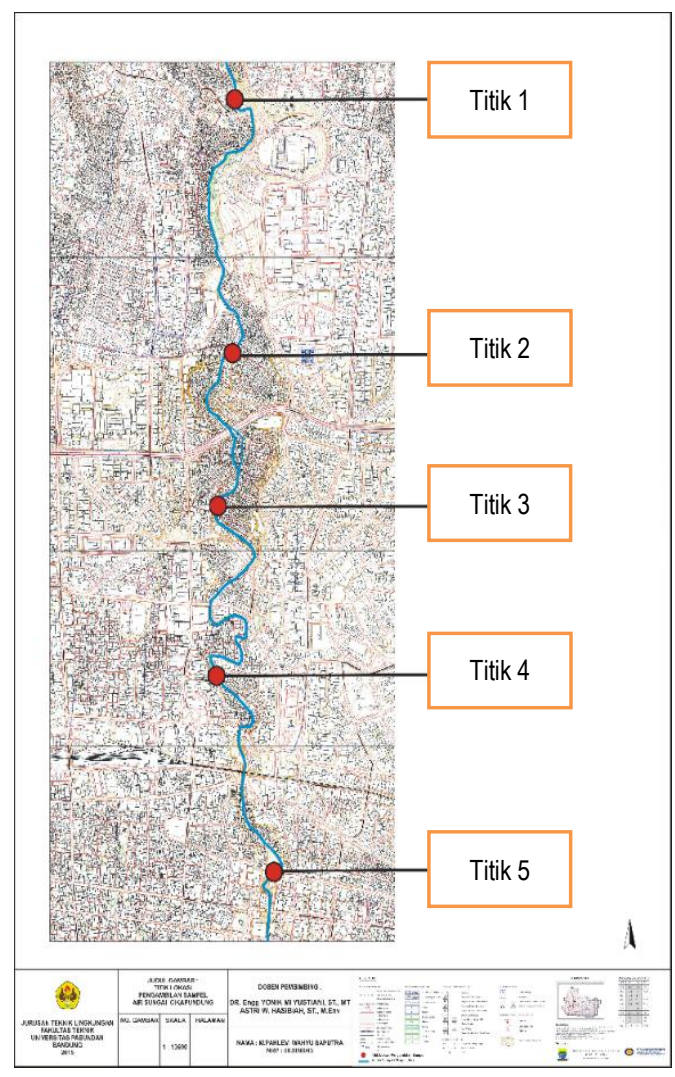

Gambar 1

Lokasi Penelitian

Pengumpulan data primer dilakukan di 5 titik yang berbeda pada Sungai Cikapundung. Untuk titik 1 (hulu) dan titik 5 (hilir) merupakan titik pengambilan sampel pada penelitian terdahulu. Dan untuk penentuan titik sampling 2, 3, 4 (tengah) dilihat dari jumlah kepadatan penduduk yang ada di sekitar Sungai
Cikapundung. Pengukuran debit terdiri dari beberapa pengukuran, diantaranya adalah pengukuran kedalaman, lebar sungai dan kecepatan aliran sungai. Pengukuran suhu dilakukan dengan menggunakan termometer. Pengukuran $\mathrm{pH}$ dan DO dilakukan dengan menggunakan alat digital seprti $\mathrm{pH}$ meter dan DO meter.

\subsection{Analisis Laboratorium}

Setelah contoh air diambil dengan prosedur yang sesuai, kemudian dilakukan pemeriksaan kualitas air di laboratorium. Pemeriksaan yang dilakukan untuk menentukan laju deoksigenasi adalah pemeriksaan parameter DO. Proses inkubasi menggunakan botol BOD, dilakukan selama 10 hari dalam inkubator $20^{\circ} \mathrm{C}$. Konsentrasi DO diukur tiap hari berdasarkan metode modifikasi Winkler (APHA [3]).

\subsection{Pengolahan Data}

Hasil pengukuran DO Loss selama 10 hari untuk tiap titik sampel di buat grafik untuk mendapatkan kurva hubungan DO Loss terhadap waktu. Nilai akumulasi DO Loss (pemakaian oksigen) yang dihasilkan pada setiap sampel digunakan dalam perhitungan laju deoksigenasinya. Perhitungan laju deoksigenasi dengan menggunakan metode Slope Method (Lin [4]) seperti berikut:

- Perhitungan meliputi penentuan pertama yakni $y, y^{\prime}, y^{\prime} y$ dan $y^{2}$. Nilai y adalah nilai akumulasi DO Loss, setelah didapat jumlah 
nilai $y, y^{\prime}, y^{\prime} y$ lalu di masukan ke dalam persamaan normal untuk menentukan Nilai $\mathrm{K}_{1}$ (laju deoksigenasi) dan La (BOD ultimate).

- Dua persamaan normal untuk menentukan $\mathrm{K}_{1}$ dan La:

$$
\begin{aligned}
& n a+b \Sigma y-\Sigma y=0 \ldots \\
& a \Sigma y+b \Sigma y^{2}-\Sigma y y^{\prime}=0 \ldots
\end{aligned}
$$

- Dari persamaan di atasmenghasilkan nilai a dan $b$, dimana nilai $\mathrm{K} 1$ dan La dapat ditentukan langsung dari hubungan berikut :

$$
\begin{aligned}
& \mathrm{K} 1=-\mathrm{b} \\
& \mathrm{L} a=-\mathrm{a} / \mathrm{b}
\end{aligned}
$$

Dimana: K1 adalah Laju deoksigenasi. La adalah BOD Ultimate.

\section{ANALISIS DAN PEMBAHASAN}

\subsection{Perhitungan Laju deoksigenasi dengan}

\section{Analisis Laboratorium}

Data hasil pengukuran DO selama 10 hari untuk tiap titik sampel dibuat grafik untuk mendapatkan kurva DO Loss terhadap waktu. Data-data tersebut dapat dilihat pada grafik dan tabel di bawah ini.

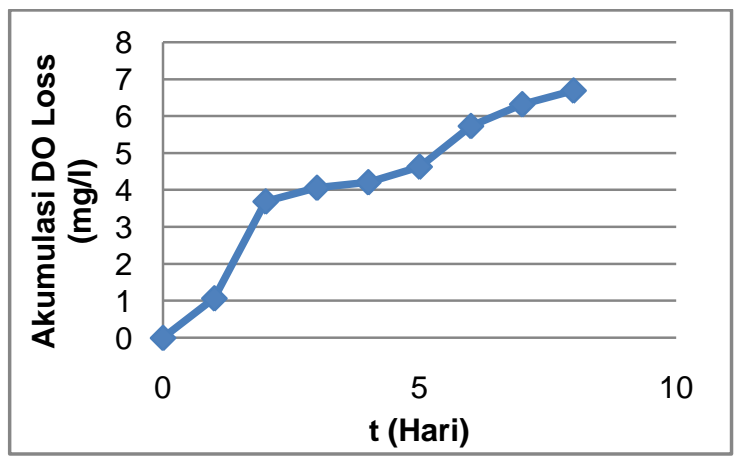

Gambar 2

Akumulasi DO Loss Terhadap Waktu

Untuk Segmen Ke-1(Hulu)
Tabel 1

Hasil Pengukuran \& Perhitungan $y^{\prime}, y \cdot y^{\prime}, y^{2}$

(Segmen 1)

\begin{tabular}{|c|c|c|c|c|c|c|}
\hline $\mathbf{t}$ & Hasil & $\begin{array}{c}\text { DO } \\
\text { Loss }\end{array}$ & $\begin{array}{c}\mathbf{y} \text { (DO } \\
\text { Loss) }\end{array}$ & $\mathbf{y}^{\prime}$ & $\mathbf{y}^{\mathbf{y}}$ & $\mathbf{y}^{\mathbf{2}}$ \\
\hline 0 & 9,88 & & 0 & & & \\
\hline 1 & 8,81 & 1,07 & 1,07 & 1,85 & 1,97 & 1,14 \\
\hline 2 & 6,19 & 2,62 & 3,69 & 1,5 & 5,52 & 13,62 \\
\hline 3 & 5,82 & 0,37 & 4,06 & 0,26 & 1,06 & 16,48 \\
\hline 4 & 5,67 & 0,15 & 4,21 & 0,29 & 1,2 & 17,72 \\
\hline 5 & 5,25 & 0,42 & 4,63 & 0,76 & 3,52 & 21,44 \\
\hline 6 & 4,15 & 1,1 & 5,73 & 0,85 & 4,84 & 32,83 \\
\hline 7 & 3,56 & 0,59 & 6,32 & 0,63 & 3,98 & 39,94 \\
\hline 8 & 2,89 & 0,67 & 6,99 & 0,06 & 0,45 & 48,86 \\
\hline 9 & & & 6,45 & 0,11 & 0,68 & 41,6 \\
\hline 10 & & & 7,2 & & & \\
\hline $\boldsymbol{\Sigma}$ & & & $\mathbf{5 0 , 3 5}$ & $\mathbf{6 , 2 9}$ & $\mathbf{2 3 , 2 2}$ & $\mathbf{2 3 3 , 6 4}$ \\
\hline & $\mathbf{K} \mathbf{1}=$ & $\mathbf{0 , 2 4}$ & & $\mathbf{L a}=$ & $\mathbf{6 , 5 4}$ & \\
\hline
\end{tabular}

Dari grafik di atas, dapat diketahui bahwa pada segmen 1 nilai pemakaian DO oleh mikroorganisme terjadi peningkatan di setiap harinya yang menyebabkan nilai DO nya turun secara kontinyu sejak pengamatan hari ke-0 sampai hari ke-10. Nilai pemakaian DO di akumulasikan sehingga di dapat nilai akumulasi DO Lossnya.

Setelah dilakukan perhitungan maka didapat nilai Laju deoksigenasi dan nilai BOD Ultimate pada setiap sampel yaitu $\mathrm{K}_{1}$ sebesar 0,24 /hari dan La sebesar 6,54 mg/l. 


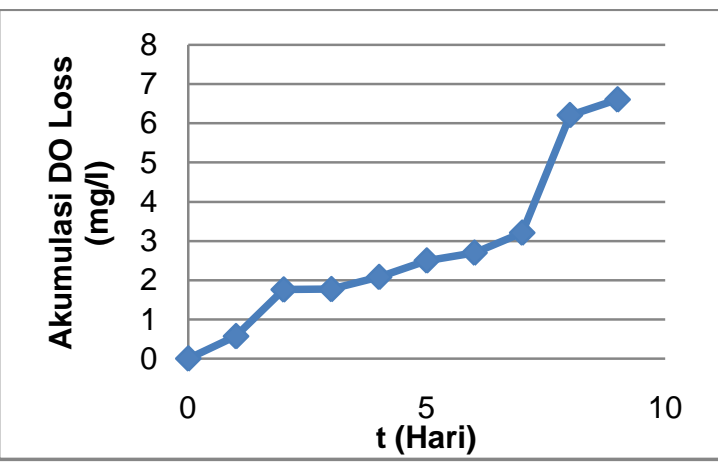

Gambar 3

Akumulasi DO Loss Terhadap Waktu Untuk Segmen Ke-2 (Tengah)

Tabel 2

Hasil Pengukuran \& Perhitungan $y^{\prime}, y \cdot y^{\prime}, y^{2}$ (Segmen 2)

\begin{tabular}{|c|c|c|c|c|c|c|}
\hline $\mathbf{t}$ & Hasil & $\begin{array}{c}\text { DO } \\
\text { Loss }\end{array}$ & $\begin{array}{c}\mathbf{y}(\mathbf{D O} \\
\text { Loss) }\end{array}$ & $\mathbf{y}^{\mathbf{\prime}}$ & $\mathbf{y}^{\mathbf{y}}$ & $\mathbf{y}^{\mathbf{2}}$ \\
\hline 0 & 11,01 & & 0 & & & \\
\hline 1 & 10,44 & 0,57 & 0,57 & 0,88 & 0,5 & 0,32 \\
\hline 2 & 9,25 & 1,19 & 1,76 & 0,6 & 1,06 & 3,1 \\
\hline 3 & 9,24 & 0,01 & 1,77 & 0,16 & 0,28 & 3,13 \\
\hline 4 & 8,93 & 0,31 & 2,08 & 0,37 & 0,76 & 4,33 \\
\hline 5 & 8,51 & 0,42 & 2,5 & 0,31 & 0,78 & 6,25 \\
\hline 6 & 8,31 & 0,2 & 2,7 & 0,36 & 0,96 & 7,29 \\
\hline 7 & 7,8 & 0,51 & 3,21 & 1,76 & 5,63 & 10,3 \\
\hline 8 & 4,8 & 3 & 6,21 & 1,7 & 10,56 & 38,56 \\
\hline 9 & 4,4 & 0,4 & 6,61 & 0,3 & 1,98 & 43,69 \\
\hline 10 & 4,2 & 0,2 & 6,81 & & & \\
\hline $\boldsymbol{\Sigma}$ & \multicolumn{7}{|c|}{} & & $\mathbf{3 4 , 2 2}$ & $\mathbf{6 , 4 3}$ & $\mathbf{2 2 , 5 1}$ & $\mathbf{1 1 6 , 9 8}$ \\
\hline & $\mathbf{K}_{\mathbf{1}}=$ & $\mathbf{0 , 1 3}$ & & La & $\mathbf{9 , 2 3}$ & \multicolumn{1}{|l}{} \\
\hline
\end{tabular}

Dari grafik di atas, dapat diketahui bahwa pada segmen 2 nilai pemakaian DO oleh mikroorganisme terjadi peningkatan di setiap harinya yang menyebabkan nilai DO nya turun secara kontinyu sejak pengamatan hari ke-0 sampai hari ke-10. Nilai pemakaian DO di akumulasikan sehingga di dapat nilai akumulasi DO Lossnya. Setelah dilakukan perhitungan maka didapat nilai laju deoksigenasi dan nilai BOD Ultimate pada setiap sampel yaitu $\mathrm{K}_{1}$ sebesar 0,13 /hari dan La sebesar 9,23 mg/l.

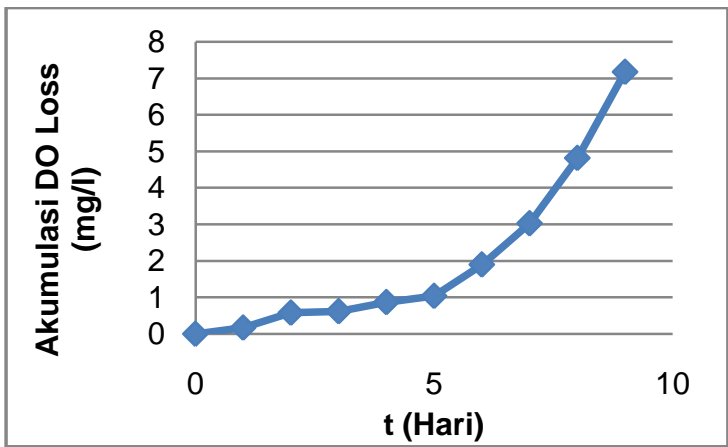

Tabel 3

Hasil Pengukuran \& Perhitungan y', y.y', $y^{2}$ (Segmen 3)

\begin{tabular}{|c|c|c|c|c|c|c|}
\hline $\mathbf{t}$ & Hasil & $\begin{array}{c}\text { DO } \\
\text { Loss }\end{array}$ & $\begin{array}{c}\mathbf{y} \text { (DO } \\
\text { Loss) }\end{array}$ & $\mathbf{y}^{\prime}$ & $\mathbf{y . y}^{\prime}$ & $\mathbf{y}^{\mathbf{2}}$ \\
\hline 0 & 7,18 & & 0 & & & \\
\hline 1 & 7,01 & 0,17 & 0,17 & 0,29 & 0,05 & 0,03 \\
\hline 2 & 6,6 & 0,41 & 0,58 & 0,23 & 0,13 & 0,34 \\
\hline 3 & 6,56 & 0,04 & 0,62 & 0,15 & 0,09 & 0,38 \\
\hline 4 & 6,31 & 0,25 & 0,87 & 0,21 & 0,18 & 0,76 \\
\hline 5 & 6,14 & 0,17 & 1,04 & 0,52 & 0,54 & 1,08 \\
\hline 6 & 5,28 & 0,86 & 1,9 & 1 & 1,89 & 3,61 \\
\hline 7 & 4,15 & 1,13 & 3,03 & 1,46 & 4,42 & 9,18 \\
\hline 8 & 2,36 & 1,79 & 4,82 & 2,08 & 10 & 23,23 \\
\hline 9 & & & 7,18 & & & \\
\hline 10 & & & & & & \\
\hline $\boldsymbol{\Sigma}$ & & & $\mathbf{2 0 , 2 1}$ & $\mathbf{5 , 9 2}$ & $\mathbf{1 7 , 3}$ & $\mathbf{3 8 , 6 1}$ \\
\hline & $\mathbf{K}_{\mathbf{1}}=$ & $\mathbf{0 , 1 9}$ & & La= & $\mathbf{6 , 4 2}$ & \multicolumn{1}{l|}{} \\
\hline
\end{tabular}


Dari grafik di atas, dapat diketahui bahwa pada segmen 3 nilai pemakaian DO oleh mikroorganisme terjadi peningkatan di setiap harinya yang menyebabkan nilai DO nya turun secara kontinyu sejak pengamatan hari ke-0 sampai hari ke-10. Nilai pemakaian DO di akumulasikan sehingga di dapat nilai akumulasi DO Lossnya.

Setelah dilakukan perhitungan maka didapat nilai laju deoksigenasi dan nilai BOD Ultimate pada setiap sampel yaitu $\mathrm{K}_{1}$ sebesar 0,19 /hari dan La sebesar 6,42 mg/l.

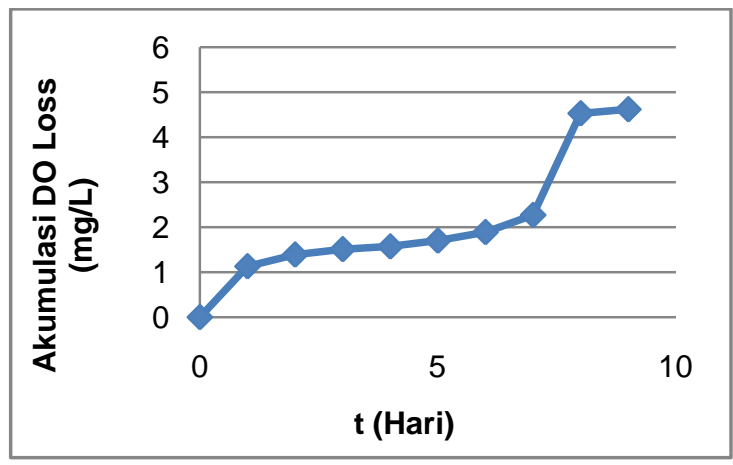

Gambar 6

Akumulasi DO Loss Terhadap Waktu Untuk Segmen Ke-5(Hilir)

Dari grafik di atas, dapat diketahui bahwa pada segmen 5 nilai pemakaian DO oleh mikroorganisme terjadi peningkatan di setiap harinya yang menyebabkan nilai DO nya turun secara kontinyu sejak pengamatan hari ke-0 sampai hari ke-10. Nilai pemakaian DO di akumulasikan sehingga di dapat nilai akumulasi DO Lossnya.
Tabel 5

Hasil Pengukuran \& Perhitungan y', y.y', $y^{2}$

(Segmen 5)

\begin{tabular}{|c|c|c|c|c|c|c|}
\hline$t$ & Hasil & $\begin{array}{c}\text { DO } \\
\text { Loss }\end{array}$ & $\begin{array}{l}\text { y (DO } \\
\text { Loss) }\end{array}$ & $y^{\prime}$ & y.y' & $y^{2}$ \\
\hline 0 & 10,45 & & 0 & & & \\
\hline 1 & 9,35 & 1,1 & 1,1 & 2,59 & 2,84 & 1,21 \\
\hline 2 & 5,28 & 4,07 & 5,17 & 2,6 & 13,44 & 26,73 \\
\hline 3 & 4,15 & 1,13 & 6,3 & 0,82 & 5,13 & 39,69 \\
\hline 4 & 3,65 & 0,5 & 6,8 & 0,32 & 2,18 & 46,24 \\
\hline 5 & 3,51 & 0,14 & 6,94 & 1,24 & 8,61 & 48,16 \\
\hline 6 & 1,17 & 2,34 & 9,28 & & & \\
\hline 7 & & & & & & \\
\hline 8 & & & & & & \\
\hline 9 & & & & & & \\
\hline 10 & & & & & & \\
\hline$\Sigma$ & & & 35,59 & 7,56 & 32,2 & 162,03 \\
\hline & $\mathrm{K}_{1}=$ & 0,08 & & $L a=$ & 15,75 & \\
\hline
\end{tabular}

Setelah dilakukan perhitungan maka didapat nilai laju deoksigenasi dan nilai BOD Ultimate pada setiap sampel yaitu $\mathrm{K}_{1}$ sebesar 0,08 /hari dan La sebesar 15,75mg/l.

Tabel 6 memperlihatkan rekapitulasi laju deoksigenasi dan nilai BOD Ultimate yang diperoleh dari analisis laboratorium.

Secara keseluruhan nilai rentang laju deoksigenasi dan BOD Ultimate dengan menggunakan analisis laboratorium di Sungai Cikapundung adalah berkisar antara 0,03 0,24 per hari $\left(\mathrm{K}_{1}\right)$ dan 6,42 - 17,67 mg/L (La). 
Tabel 6

Nilai Laju Deoksigenasi dan BOD Ultimate Dengan Menggunakan Analisis Laboratorium

\begin{tabular}{|c|c|c|}
\hline $\begin{array}{c}\text { Titik } \\
\text { Sampling }\end{array}$ & $\begin{array}{c}\text { Laju Deoksigenasi } \\
\mathbf{K}_{\mathbf{1}} \\
\text { (per hari) }\end{array}$ & $\begin{array}{c}\text { BOD ultimate } \\
\text { La } \\
\text { (mg/L) }\end{array}$ \\
\hline Segmen 1 (Hulu) & 0,24 & 6,54 \\
\hline $\begin{array}{c}\text { Segmen 2 } \\
\text { (Tengah) }\end{array}$ & 0,13 & 9,23 \\
\hline $\begin{array}{c}\text { Segmen 3 } \\
\text { (Tengah) }\end{array}$ & 0,19 & 6,42 \\
\hline $\begin{array}{c}\text { Segmen 4 } \\
\text { (Tengah) }\end{array}$ & 0,03 & 17,67 \\
\hline Segmen 5 (Hilir) & 0,08 & 15,75 \\
\hline
\end{tabular}

\subsection{Perhitungan Laju Deoksigenasi}

\section{Menggunakan Rumus Empiris}

Setelah dilakukan pengukuran kedalaman Sungai Cikapundung pada segmen hulu maupun segmen hilir diperoleh hasil yang tidak melebihi 1,5 meter, sehingga rumus yang digunakan adalah sebagai berikut :

$$
K_{1}=0,3 \times\left(\frac{H}{8}\right)^{-0,434}
$$

\section{Dimana :}

$\mathrm{K}_{1}=$ Koefisien deoksigenasi $\left(\right.$ hari $^{-1}$ )

$\mathrm{H}=$ Kedalaman $(\mathrm{m})$.

Setelah dilakukan perhitungan maka didapat nilai laju deoksigenasi $\left(\mathrm{K}_{1}\right)$ dengan menggunakan rumus empiris untuk setiap sampel adalah sebagai berikut:
Tabel 7

Nilai Laju Deoksigenasi Dengan Menggunakan Rumus Empiris

\begin{tabular}{|c|c|c|c|}
\hline \multirow{2}{*}{$\begin{array}{c}\text { Titik } \\
\text { Sampling }\end{array}$} & \multicolumn{2}{|c|}{ Kedalaman (H) } & $\begin{array}{c}\text { Laju Deoksigenasi } \\
\mathbf{K}_{\mathbf{1}} \\
\text { (per hari) }\end{array}$ \\
\hline $\begin{array}{c}\text { Segmen 1 } \\
\text { (Hulu) }\end{array}$ & 0,70 & 2,30 & 0,51 \\
\hline $\begin{array}{c}\text { Segmen 2 } \\
\text { (Tengah) }\end{array}$ & 0,53 & 1,74 & 0,58 \\
\hline $\begin{array}{c}\text { Segmen 3 } \\
\text { (Tengah) }\end{array}$ & 0,40 & 1,31 & 0,66 \\
\hline $\begin{array}{c}\text { Segmen 4 } \\
\text { (Tengah) }\end{array}$ & 0,73 & 2,40 & 0,50 \\
\hline $\begin{array}{c}\text { Segmen 5 } \\
\text { (Hilir) }\end{array}$ & 0,63 & 2,07 & 0,54 \\
\hline
\end{tabular}

Secara keseluruhan apabila digabungkan dan diambil nilai rentang laju deoksigenasi $\left(\mathrm{K}_{1}\right)$ pada Sungai Cikapundung berkisar antara 0,50 hingga 0,66 per hari.

\section{KESIMPULAN}

Hasil penelitian ini memperlihatkan bahwa nilai rentang laju deoksigenasi $\left(\mathrm{K}_{1}\right)$ dengan menggunakan analisis laboratorium pada Sungai Cikapundung berkisar antara 0,03 hingga 0,24 per hari dan nilai BOD Ultimate berkisar antara 6,42 hingga 15,75 mg/L. Sedangkan untuk nilai rentang koefisien deoksigenasi dengan menggunakan rumus empiris pada Sungai Cikapundung berkisar antara 0,50 hingga 0,66 per hari.

Dari hasil di atas, nilai rentang laju deoksigenasi $\left(\mathrm{K}_{1}\right)$ dengan menggunakan 
analisis laboratorium lebih kecil dibandingkan nilai rentang laju deoksigenasi $\left(\mathrm{K}_{1}\right)$ dengan menggunakan rumus empiris, hal ini terjadi kemungkinan aktivitas mikroorganisme dalam menguraikan materi organik yang terkandung di dalam air Sungai Cikapundung relatif rendah karena adanya inhibitor yang menghambat pertumbuhan mikroorganisme seperti limbah industri yang mengandung logam berat. Selain itu, limbah medis dari rumah sakit atau klinik juga seperti zat kimia beracun atau antibiotik yang dapat menghambat aktivitas bahkan akan mematikan mikroorganisme.

\section{DAFTAR PUSTAKA}

[1] Rahayu, Surtikanti, dan Bahri. 2012. Kajian Relung Ekologi Benthos Di
Sungai Cikapundung Hilir Yang Mengalami Pencemaran Limbah Domestik Dan Industri Tekstil. Universitas Pendidikan Indonesia.

[2] Robiahadawiyah, 2011. Pencemaran Air Sungai Cikapundung, [Online]. http://bebasbanjir2025.wordpress.co m/2011/08/19/pencemaran -air-disungai-cikapundung/. [05 Januari 2016]

[3] APHA/AWWA/WEF. 2012. Standard Methods for the Examination of Water and Wastewater, $22^{\text {nd }}$ Edition

[4] Lin, S.D., 2007. Water and Wastewater Calculation Manual. $2^{\text {nd }}$. McGraw-Hill 